\title{
A foresight-oriented service design approach to foster longer-term thinking and sustainable practices
}

\author{
Cathrine Kulsbjerg Løgagera, Luca Simeoneb, G. Mauricio Mejíac \\ aService Design Lab, Aalborg University \\ bService Design Lab, Aalborg University \\ 'The Design School, Arizona State University \\ *Corresponding author email: cathrine_loegager@hotmail.com
}

\begin{abstract}
:
This paper explores how service design practitioners can incorporate foresight methods as a way to foster longer-term thinking and sustainable practices in design projects. Our findings highlight that service design agencies might not always be equipped to offer to their clients a structured integrated foresight and service design approach. This paper presents the preliminary results of a 15-month study, which was also articulated into a series of co-creation workshops aimed at exploring possible ways in which foresight can be integrated within service design practices.
\end{abstract}

Keywords: service design, foresight, long-term thinking, sustainable practices

\section{Introduction}

In the past few years, a number of researchers explored interplay of design and foresight (Candy \& Dunagan, 2017; Hines \& Zindato, 2016; Römgens, 2016). Design practitioners and researchers extensively examined hybrid approaches combining design and foresight processes, for example producing provocative fictional prototypes (Dunne and Raby, 2013), making future scenarios experiential and immersive (Candy \& Dunagan, 2017) and generating diegetic prototypes to enrich storytelling (Sterling, 2009). Design artifacts - visualizations, videos, prototypes - can materialize and translate outcomes from foresight into vivid and engaging formats, which can be appreciated by a wide audience that is not necessarily well-versed in foresight (Hartman, 2016).

One particular area of interest has been how the combination of design and foresight can be used as a core method to foster longer-term thinking and to instill more sustainable ways of thinking (Reitsma et al., 2017). Here, studies are sparse and little has been said about how the combination of service design and foresight can foster longer-term and sustainable practices in design projects. 
Our paper intends to address this gap by investigating a project carried out for a prominent international design consulting firm, which recently decided that a concern over environmental sustainability should be a core element of their design projects. To this end, this firm was convinced that it needed a more structured approach to support their service designers in thinking longer-term and, as such, becoming more aware of the long-term environmental and social impact of their design projects (Klauer et al., 2013). Within this context, we carried out a 15-month study, in which together with an array of service designers and professional futurists - we (1) examined how this firm currently use foresight in their service design offering and (2) co-created a preliminary structured framework for a workshop that combines methods from both disciplines.

\section{Literature review}

\subsection{The complexity of integrating design and foresight}

The integration of design and foresight can produce visions of desirable futures through systematic thinking and an active experimentation to gather new knowledge and learning (Bühring \& Liedtka, 2018). A design-inspired foresight approach and its potential to create "richer, more accessible and immediate" formats of future events (Kelliher \& Byrne, 2015, p. 38) can contribute to the organizations' capacity to make sense of the complexity of the future (Buhring, 2017). Indeed, organizations can adopt new ways of anticipating and influencing change, which can be done with imagination and holistic perspectives in addition to analytical thinking (Buehring \& Bishop, 2020).

Several authors pointed to the need of stricter integration between design and foresight (e.g. Bühring \& Liedtka, 2018; Candy \& Potter, 2019). A creative and potentially challenging tension originates from the broad application of design to generate a portfolio of very diverse and at times utopian or provocative possibilities and the stricter orientation of foresight toward generating plausible scenarios on the basis of trends and uncertainties (Bühring \& Vittachi, 2019). As such, their integration brings some concealed complexity.

The particular interest of this paper is how such integration of design and foresight can occur within the domain of design projects concerned with sustainability. Although in the practice of foresight a relatively consistent number of publications and approaches have focused on sustainability (e.g. Svenfelt et al., 2010, 2019), within design research and, more specifically, within service design projects, studies remain more sparse (Irwin, 2015). A critical concern elaborated in literature focusing on environmental sustainability is the need to foster long-term thinking in society (Klauer et al., 2017). Sustainability has to do with the long-term development of complex and interlinked economic, social and natural systems, which is an extremely challenging task (Baumgärtner \& Quaas, 2010). For designers to address sustainability, one must find the leverage points to foster sustainable processes by gaining an understanding of the whole system through systemic design methods (Bofylatos et al., 2012).

\subsection{Foresight in service design}

It is quite common to find considerations on how various service design methods - e.g. journey maps, system maps or scenarios - can be used to imagine future directions of services (e.g. Meroni \& Sangiorgi, 2011). Broadly, methods commonly employed in service design processes can also be used to map various possible futures and, in general, to adopt a longer-term perspective. The classical methods of journey maps and system maps can be qualified as either 'current-state' or 'future-state' if they visualize the current state or possible future states (Penin, 2018; Stickdorn et al., 2018). Occasionally, books and manuals providing compilations of design methods - not necessarily only 
limited to service design - recommend foresight methods such as trend analysis or scenario building mostly to frame design challenges and discover insights (e.g. Boeijen et al., 2014; Kumar, 2013), but they do not delve into how such foresight methods would reframe the design process or foster a systematic way of approaching the long-term perspective required to solve wicked problems. It is worth noting that both service design and foresight are future-oriented, in the sense that they work towards and around something which does not already exist. However, while foresight tends to identify and analyze long-term and future-gazing views, service design tends to keep a narrower and closer focus on the near-future ways in which services can be conceived and deployed. According to Ojasalo et al. (2015), the key reason why the two fields should be integrated is precisely to give to the designer a deep understanding of the users' needs and wants (through the service design perspective), as well as knowledge of important indicators of how the social, cultural, economic, technological and environmental contexts will unfold (through the foresight perspective).

Along these lines, a number of service design researchers propose considerations on the integrated use of foresight methods in service design. Kimbell (2014) recommends that to adopt a more strategic perspective, service designers might want to take into account the political, environmental, socio-cultural, technological, legal/regulatory and economic drivers of change that might affect a service across several time horizons (3-5 years, $5-10$ years and more than 10 years). Ferrulli et al. (2019) reported on a research project where a combination of design and foresight methods were used to invite some organizations to think both creatively and systematically about the future and these reflections, in turn, prepared the organizations to be more agile and adaptive. Ojasalo et al. (2015) proposed a conceptual framework for service innovation processes, which merges foresight and service design methods.

These theoretical contributions show that foresight has the potential to contribute to service design practices; however, field research is needed to explore how designers in the industry can or would adopt a foresight driven service design practice. Our study intends to cover this gap through a collaborative process that involved a number of service designers and professional futurists, who also through co-creation workshops - explored the following research question: How do and would service design practitioners incorporate foresight methods as a way to foster longer-term thinking and sustainable practices in design projects?

To address this question, we decided to focus on a number of commonly used foresight methods trend analysis ${ }^{1}$, scenario building ${ }^{2}$, backcasting ${ }^{3}$, and roadmapping ${ }^{4}$ - and to investigate how they interact with core service design methods (stakeholder maps, personas and user journeys).

\footnotetext{
${ }^{1}$ The goal of trend analysis is assessing trends, as "forces that have a certain influence on society, but that do not determine everything, which means that the future is not just determined by trends, but by trends and counter-trends" (Cramer et al., 2016, p. 42).

${ }^{2}$ Scenarios are narrative representations that explore potential futures that are deemed possible and the developments that may lead there (Dammers \& Langeweg, 2013).

${ }^{3}$ Backcasting can be defined "as first creating a desirable (sustainable) future vision or normative scenario, followed by looking back at how this desirable future could be achieved, before defining and planning follow-up activities and developing strategies leading towards that desirable future" (Quist \& Vergragt, 2006, p. 1028).

${ }^{4}$ Roadmapping is here seen as a method aimed at producing a visual representation that plots on a timeline actions and interactions among these actions (Römgens, 2016).
} 


\section{Methodology}

Our study unfolded across a period of 15 months and built on an array of methods to gather and analyze data and connect research insights to relevant literature: participant observation (Fetterman, 2009), expert interviews (Bryman, 2003) and co-creation workshops (Sanders \& Stappers, 2013). Our fieldwork began with a 6-month period in which one of the authors had the chance to work for the Copenhagen branch of a prominent international design consulting firm. During the fieldwork, we interacted with dozens of this firm's service designers and with additional service designers and foresight professionals with other companies. After the initial fieldwork and a first round of interviews, most of the work to collect data was carried out through four co-creation workshops in which service designers tested various combinations of service design methods and foresight methods. The workshops were run both physically and digitally and each of the foresight methods (trend analysis, scenario building, backcasting, and roadmapping) was tested several times. The workshops were used as an additional method to gather data, by observing the participants' behavior and by eliciting their reflections through dedicated discussion sessions. The idea was to combine multiple data collection and generation methods and exploit the synergistic effects of combining them via triangulation (Eisenhardt, 2002), as to reduce the bias of a single observation (Tarrow, 1995).

\section{Findings}

\subsection{The need for a more integrated approach between service design and foresight}

Data from our fieldwork showed that the design firm we studied did not follow any predefined framework or process that combine foresight and service design. If the service designers already knew how to use some foresight methods (e.g. from school or previous workplaces), they were free to apply them in their projects. However, since foresight methods were not routinely included in the firm offering to its clients, rarely was the time to work with such foresight methods adequately budgeted. As such, foresight methods were only used in a minority of the service design projects of the firm and in single phases of these projects either as a part of the preliminary research, or to support the initial ideation phases and further iteration cycles. Foresight was never prioritized or incorporated permanently through all the phases of the service design process. Nonetheless, both the firm management and most of the service designers seemed to be intrigued by the possibility of a stricter integration between foresight and service design. Particularly, they saw the potential of foresight to support that long-term thinking that is necessary when considering the impact of a service design project in terms of environmental sustainability. What they missed was a structured market offering that could be presented to their clients. The co-creation workshops described below were precisely oriented towards outlining a foresight-oriented service design framework that could become part of such a market offering.

\subsection{Outlining a foresight-oriented service design framework}

\section{Testing the interaction of foresight and service design methods}

During the first four workshops, seven Danish and international service designers worked on a service design case by combining two foresight methods with service design methods. Table 1 provides an overview of the work performed during these workshops. 
Table 1. Format of the first four co-creation workshops

What were the participants asked to do during the design case?
The service designers were asked to select a service that they frequently use, and try to futureproof it by adopting a longer-think perspective. The workshops were arranged to observe how the foresight methods 'trends' and 'backcasting' contribute to three core service design methods: user journey, stakeholder map and persona. The goal was to investigate how a future-gazing perspective can affect the service design process, the mindset of the designers, and the outcome of the design process.

- 30 minutes: Mapping the current service offering through user journey, stakeholder map and persona in order to create a common understanding of the key aspects of the service. Here, the facilitator could observe how the service design methods were used without the future-gazing perspective.

- 30 minutes: Interviewing the participants to check their expertise in relation to foresight and investigate if and why they currently use foresight methods in their design process.

- 30 minutes: Exercises with foresight, in which the participants had to expand the time horizon of their thinking and futureproof the service offering using trend analysis or backcasting. The facilitator could observe the participants' experience with the foresight methods and how the use of the service design methods changed when incorporating a future-gazing perspective.

- 30 minutes: Discussion to gather the reflections of the participants on the previous exercises. designers had to discuss how these trends would affect the service and business offering by evaluating and future-proofing the current representation of the user journey, stakeholder map and persona. The goal was to observe how 
the exploratory trend analysis contributed to the design process and the focus point.

How was the backcasting method used?

The service designers had to develop a future vision of 10-15 years of the chosen service offering, and strategize on how to reach that vision. Future scenarios were presented to the service designers in order to inspire them to create a future vision. Service designers also had to discuss which necessary strategic changes had to be drawn in order to achieve the future vision. The goal of the exercise was to observe how the normative backcasting method changed the scope of service design methods and contributed to the design process.

The data were analyzed by using the method 'creating a research wall' (Stickdorn et al., 2018) by clustering the findings into categories and identifying relevant patterns in the results. The findings were validated and triangulated by comparing and discussing the data from all workshops with experts to create a coherent justification of the insights.

Generally speaking, the service designers expressed the view that by incorporating foresight methods into the service design process, possible futures become more tangible. In addition, they stated that when forced to think in longer terms, their thinking became more critical and helped to set more robust goals for the project.

Foresight methods can also be used to validate key assumptions and decisions during the design process. The foresight method 'Trend analysis' helped the service designers reflect upon future constraints (e.g., in relation to climate change) and demands of the market and of the users, which made the designers gain a longer term perspective: "It taught me to include more factors when creating a strategy for my organization" (co-creation workshop, 3 March 2020). The foresight method 'Backcasting' helped the service design process be more focused and targeted. The future vision and goals gave the service designers an anchor point to justify their design decisions: "Having a future vision and setting goals to achieve that vision helped us to take action to achieve that future" (co-creation workshop, 13 March 2020). Backcasting was also considered key to align design decisions to broader goals in terms of environmental sustainability (e.g., the Sustainable Development Goals).

The workshop also highlighted some potential pitfalls. There is a risk of making the trend analysis too general and broad, which, in turn, can make it complex to innovate the service offering. We also realized that it would have been beneficial if the trend analysis had been combined with the foresight method 'Scenario building', which could have translated the trends into narratives and perceived as closer to the context of the design brief (Nekkers, 2016). The service designers also pointed out that although the backcasting method provided a future anchor point, it was difficult to define the more operational steps to reach this anchor point. Here, the foresight method "Roadmapping" could have helped to translate the future goals and visions into a concrete action plan to reach them.

The co-creative workshops showed a clear difference in how the service design methods were used before and after the foresight methods had been presented to the service designers. After being 
exposed to foresight, the user journey was used to systematically identify the touchpoints that could be affected by relevant trends. The trend analysis made the service designers realize where in the user journey they needed to be aware of possible future changes. The persona was used to identify future end-users and thereby as a way to innovate the service according to these future personas' needs and wants: "The future perspective made us realize that another group of customers could be more valuable for us to focus on" (co-creation workshop, 6 March 2020). The stakeholder map was used to identify new long-term strategic partnerships, which could also counteract possible disruptive events caused by climate change.

\section{Elaboration and validation of the framework}

Lastly, the authors organized two additional workshops in which a framework for a foresightoriented service design process was outlined and then tested in collaboration with service designers and foresight professionals. The foresight methods scenario building and roadmapping were now also incorporated in the framework and assessed to accommodate the shortcomings emerged from the first four workshops described above. Figure 1 reports on these workshops' findings, i.e. the definition of a framework that consists of (1) a scoping phase which is when the service designer conducts research and (2) of a co-creative phase, within which the service designer and the client jointly explore various future service trajectories and the long-term impact that such service trajectories might have for the client.

\begin{tabular}{|c|c|c|c|}
\hline $\begin{array}{c}\text { Scoping } \\
\text { Participants: Design Team }\end{array}$ & \multicolumn{3}{|c|}{$\begin{array}{c}\text { Co-creative } \\
\text { Participants: Design Team \& The Client }\end{array}$} \\
\hline Phase: Scanning & Phase: Mapping & Phase: Mounting & Phase: Visioning \\
\hline $\begin{array}{l}\text { Focus: } \\
\text { Foresight methods }\end{array}$ & $\begin{array}{c}\text { Focus: } \\
\text { Service Design methods }\end{array}$ & $\begin{array}{l}\text { Focus: } \\
\text { Foresight and Service } \\
\text { Design methods }\end{array}$ & $\begin{array}{l}\text { Focus: } \\
\text { Foresight and Service } \\
\text { Design methods }\end{array}$ \\
\hline $\begin{array}{l}\text { Goal: } \\
\text { The design team gains } \\
\text { an understanding of } \\
\text { the future external } \\
\text { environment. }\end{array}$ & $\begin{array}{l}\text { Goal: } \\
\text { The design team and } \\
\text { the client will map the } \\
\text { internal and external } \\
\text { service landscape } \\
\text { to gain a common } \\
\text { understanding of } \\
\text { current constraints. }\end{array}$ & $\begin{array}{l}\text { Goal: } \\
\text { The design team and } \\
\text { the client will create a } \\
\text { desired future vision } \\
\text { and align it with the } \\
\text { service landscape to } \\
\text { facilitate innovation. }\end{array}$ & $\begin{array}{l}\text { Goal: } \\
\text { The design team and } \\
\text { the client will make } \\
\text { actionable future goals } \\
\text { and define a roadmap. }\end{array}$ \\
\hline $\begin{array}{l}\text { Methods: } \\
\text { Trends } \\
\text { Scenario scoped to } \\
\text { the organization. }\end{array}$ & $\begin{array}{c}\text { Methods: } \\
\text { User journey } \\
\text { Persona } \\
\text { Stakeholder map }\end{array}$ & $\begin{array}{c}\text { Methods: } \\
\text { Backcasting } \\
\text { User Journey } \\
\text { Persona } \\
\text { Stakeholder map }\end{array}$ & $\begin{array}{c}\text { Methods: } \\
\text { Roadmapping }\end{array}$ \\
\hline
\end{tabular}


During the first phase (labeled "scanning"), the service designer (potentially, in conjunction with foresight professionals) prepares the workshop by carrying out an analysis of relevant trends for the client and its service offering. During our workshops, the service designers ranked and evaluated the trends by creating a "scenario cross", a 2x2 matrix with four quadrants that explore various scenarios in relation to two polarized sets of variables (Nekkers, 2016). Next, the service designers went through an exercise in long-term thinking and reflected on the most strategic choices and dilemmas for each of the four quadrants in the scenario cross, particularly with regard to environmental sustainability. The outcome of this exercise is a set of scenarios. The second phase (labeled "mapping") is designed to give both the service designers and the client an understanding of the current service and its internal constraints. Service design methods are employed to collaboratively map the current user journey and the current personas and to design a stakeholder map. In the third phase (labeled "mounting"), insights from the previous two phases are used to create a desired future state for the service by using the backcasting method. The work starts by sharing with the client the scenarios already elaborated in the first phase. These scenarios are discussed in light of defining a desirable future state, which can also serve as a basis for the backcasting process. Subsequently, the service designers and the client evaluate the current user journey, the current persona and current stakeholder map to understand how they can be improved and reoriented towards the desirable future state. The fourth phase is the "visioning" phase, which, through a roadmapping exercise, provides a more granular plan on how the desired future state can be reached. This final phase makes the previous phases more tangible by creating actionable plans of how to move towards the future visions and goals.

On the one hand, the framework was a tool used to run and facilitate the final two workshops. On the other, it is, in itself, a process that can be potentially replicated in real-life service design projects - even though we realize that further evaluation is needed to validate the framework in multiple contexts of use.

\section{Discussion}

Previous studies have already signposted the importance of foresight in informing design processes (Ferrulli, Giraldo Nohra, et al., 2019; Gordon et al., 2019; Ojasalo \& Ojasalo, 2015). The current complexity, uncertainty and volatility of our macro environment makes it essential for organizations to adopt a longer-thinking timeframe for their strategic plans, so that their service offering remains attractive in the future (Bühring \& Liedtka, 2018) and they can not only cope with the effects of climate change but rather contribute to a more sustainable future (Reitsma et al., 2017).

Our understanding is that these existing studies can benefit from a more fine-grained analysis of the interplay between foresight and service design practice. Thus, in our study, we focused on how foresight methods can be better integrated into current service design practice, thus fostering longer-term thinking and greater attention towards the social and environmental impact of design projects. Our findings highlighted that service design agencies might not always be equipped to offer to their clients a structured integrated foresight and service design approach. Within the agency that we examined, foresight methods were not incorporated in a structured and coherent way with service design practice. Generally, service designers did not have the capabilities to conduct foresight projects that systematically scope into the future. This lack of offering was also perhaps motivated by (or, from another perspective, might even contribute to) a lack of interest from clients, which did not seem willing to prioritize future-scoping projects which did not give an immediate return on investment. Yet, the service designers that we engaged in our study confirmed the potential of combining foresight with service design. The framework could be a stepping stone towards 
embedding the knowledge of foresight in the service design community. The framework can be used as a structured step-by-step guide of when and how to incorporate foresight methods in the design process and thereby also as a learning tool to understand how foresight methods affect both the service design methods and key phases of the design process. Based on our findings, we identified new uses of service design methods to facilitate change and foresee future stakeholders (Figure 2).

\section{Standard use}

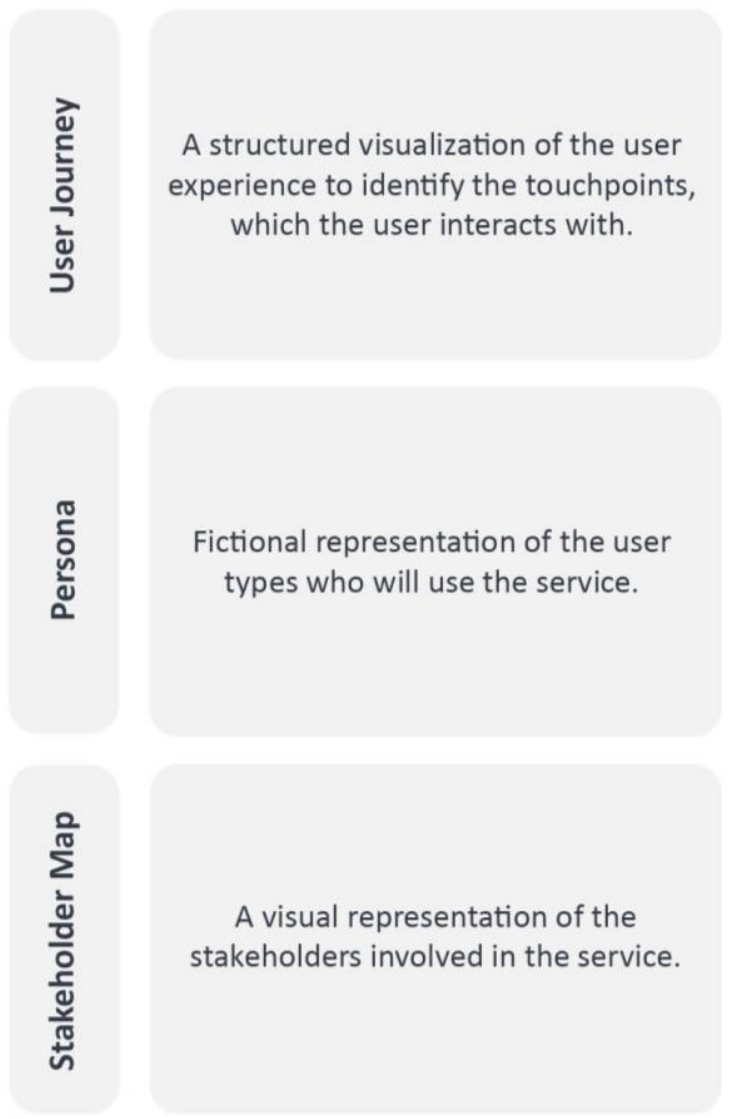

Used with foresight methods

\begin{abstract}
Facilitates long-term thinking through a focus on where and how to change the service offering according to the possible or preferred future.
\end{abstract}

Focusing on the future personas forces service designers in considering the long-term wants and needs of the service stakeholders and, thus, in better assessing the impact of design projects in relation to social and environmental sustainability.
Facilitates the process of transforming the knowledge of the future, into identifying new strategic stakeholders and evaluating the value of the current stakeholders.

Figure 2. How service design methods can change when used with foresight

While the idea that foresight provides a longer-term perspective to designers is not new, we found intriguing that our framework enabled a multiperspectival journey. In our workshops, it was observed that the foresight-driven exploratory approach (trend analysis and scenario building) functioned as a source of inspiration of possible futures and helped the service designers understand how these futures would affect the service offering. Conversely, the foresight-driven normative approach (backcasting and roadmapping) pushed the service designers to define a preferred future service, targets to aim for, and a series of actions that could guide the implementation of the future service (Figure 3). 

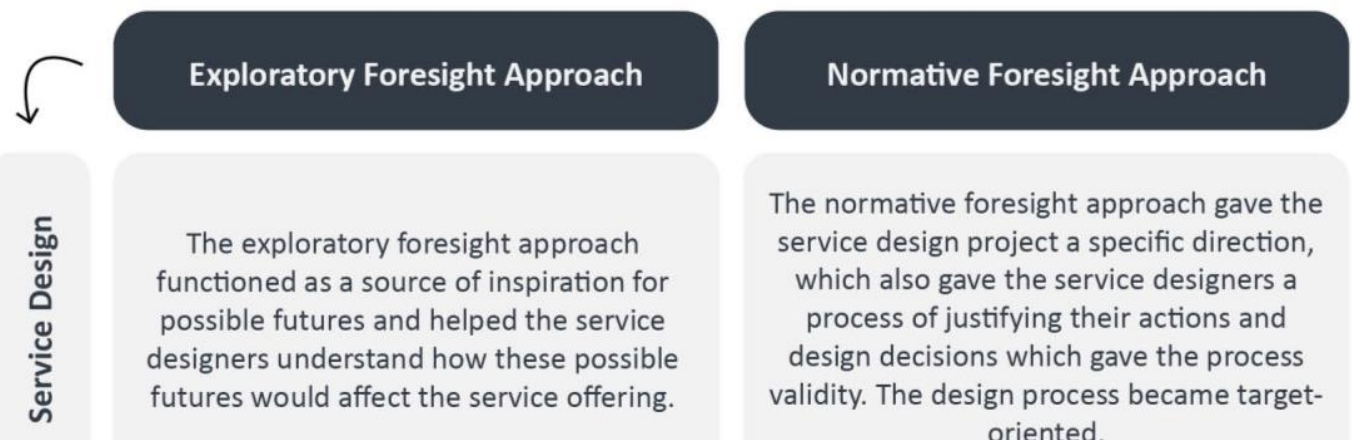

The normative foresight approach gave the service design project a specific direction, which also gave the service designers a process of justifying their actions and design decisions which gave the process validity. The design process became targetoriented.

Figure 3. Foresight-driven exploratory and normative approaches in service design projects

The combination of exploratory and normative perspectives provided by the different foresight methods across the framework exposed the service designers to multiple viewpoints: (a) exploring multiple (plausible, possible) futures vs. concentrating on a desirable future and (b) focusing on current service vs. focusing on the future service. On the one hand, foresight fueled divergent thinking and invited service designers to explore multiple possibilities, on the other, it fostered convergent thinking when service designers were invited to concentrate on a single desirable future state. Management studies showed that alternating between these contrasting viewpoints is a good way for organizations to foster and manage strategic flexibility (Raynor, 2007) and to elaborate and manage complexity rather than reduce it (Friend \& Hickling, 2012). In other words, the long-term thinking needed to support sustainability (Klauer et al., 2017) can be supported by the deliberate alternance of divergent and convergent thinking fueled by design.

Along these lines, our study provided some preliminary reflections on how service designers can use the foresight methods 'trends' and 'scenarios' to translate the wicked challenges of sustainability into concrete understandings of how a sustainable future can look for their clients. Using the 'backcasting' method, service designers can anchor the insights from the 'trends' and 'scenarios' into specific sustainable visions and goals.

\section{References}

Baumgärtner, S., \& Quaas, M. (2010). What is sustainability economics? Ecological Economics, 69(3), 445-450. https://doi.org/10.1016/j.ecolecon.2009.11.019

Boeijen, A. van, Daalhuizen, J., Schoor, R. van der, \& Zijlstra, J. (2014). Delft Design Guide: Design Strategies and Methods. BIS Publishers.

Bofylatos, S., Spyrou, T., Darzentas, J. S., \& Darzentas, J. (2012). Designing for Sustainability: A generic Framework. 11.

Bryman, A. (2003). Research Methods and Organization Studies. Routledge.

Buehring, J., \& Bishop, P. C. (2020). Foresight and Design: New Support for Strategic Decision Making. She Ji: The Journal of Design, Economics, and Innovation, 6(3), 408-432. https://doi.org/10.1016/j.sheji.2020.07.002

Buhring, J. (2017). Design-inspired foresight: Strategic foresight techniques for preferable futures. 4, 1115-1130. https://doi.org/10.21606/dma.2017.48 
Bühring, J., \& Liedtka, J. (2018). Embracing systematic futures thinking at the intersection of Strategic Planning, Foresight and Design. Journal of Innovation Management, 6(3), 134-152.

Bühring, J., \& Vittachi, N. (2019, June 19). Bringing futures scenarios to life with video animation: A case of disseminating research to nonexpert audiences. Proceedings of the Academy for Design Innovation Management Conference.

Candy, S., \& Dunagan, J. (2017). Designing an experiential scenario: The People Who Vanished. Futures, 86, 136-153. https://doi.org/10.1016/j.futures.2016.05.006

Candy, S., \& Potter, C. (2019). Design and Futures (Introduction).

Cramer, T., Heselmans, C., \& Van der Duin, P. (2016). Trend Analysis. In P. Van der Duin (Ed.), Foresight in Organizations. Routledge.

Dammers, E., \& Langeweg, S. (2013). Scenario's maken voor milieu, natuur en ruimte: Een handreiking. PBL.

Eisenhardt, K. M. (2002). Building theories from case study research. In M. Huberman \& B. Miles Matthew B. (Eds.), The Qualitative Researchers' Companion. SAGE Publications.

Ferrulli, E., Giraldo Nohra, C., \& Barbero, S. (2019, June 18). Systemic Design for Policy Foresight: Towards sustainable future. Proceedings of Academy for Design Innovation Management Conference.

Ferrulli, E., Nohra, C. G., \& Barbero, S. (2019). Systemic Design for Policy Foresight: Conference Proceedings of the Academy for Design Innovation Management, 2(1), 1150-1161-1150-1161. https://doi.org/10.33114/adim.2019.04.366

Fetterman, D. M. (2009). Ethnography: Step-by-Step (3rd edition). SAGE Publications.

Friend, J., \& Hickling, A. (2012). Planning Under Pressure (3rd edition). Routledge.

Gordon, A. V., Rohrbeck, R., \& Schwarz, J. O. (2019, April 7). Faster Horses Won't Work: Bridging Strategic Foresight and Design-Based Innovation-Research-Aarhus University. Proceedings of the IPSIM Connects Conference. https://pure.au.dk/portal/en/publications/faster-horses-wontwork-bridging-strategic-foresight-and-designbased-innovation(73f4fee0-f498-419c-8d29de512b3f046b).html

Hartman, R. (2016). Foresight and Creativity. In P. Van der Duin (Ed.), Foresight in Organizations. Routledge.

Hines, A., \& Zindato, D. (2016). Designing Foresight and Foresighting Design: Opportunities for Learning and Collaboration via Scenarios. World Futures Review, 8(4), 180-192. https://doi.org/10.1177/1946756716672477

Kelliher, A., \& Byrne, D. (2015). Design futures in action: Documenting experiential futures for participatory audiences. Futures, 70, 36. https://doi.org/10.1016/j.futures.2014.12.004

Kimbell, L. (2014). The Service Innovation Handbook. BIS Publishers. http://serviceinnovationhandbook.org/methods/

Klauer, B., Manstetten, R., Petersen, T., \& Schiller, J. (2013). The art of long-term thinking: A bridge between sustainability science and politics. Ecological Economics, 93, 79-84. https://doi.org/10.1016/j.ecolecon.2013.04.018

Klauer, B., Manstetten, R., Petersen, T., \& Schiller, J. (2017). Sustainability and the Art of Long-Term Thinking. Routledge.

Kumar, V. (2013). 101 Design Methods: A Structured Approach for Driving Innovation in Your Organization (Original edition). John Wiley \& Sons.

Meroni, A., \& Sangiorgi, D. (2011). Design for Services. Gower Publishing.

Nekkers, J. (2016). Developing Scenarios. In P. Van der Duin (Ed.), Foresight in Organizations. Routledge. 
Ojasalo, J., \& Ojasalo, K. (2015, June 9). Using Service Logic Business Model Canvas in Lean Service Development. Proceedings of the 2015 Naples Forum on Service,.

Penin, L. (2018). Designing the invisible. Bloomsbury.

Quist, J., \& Vergragt, P. (2006). Past and future of backcasting: The shift to stakeholder participation and a proposal for a methodological framework. Futures, 38(9), 1027-1045. https://doi.org/10.1016/j.futures.2006.02.010

Raynor, M. E. (2007). The Strategy Paradox: Why Committing to Success Leads to Failure. Doubleday.

Reitsma, L., Wessman, S., \& Önnevall, E. (2017). 'I Believe in That Version of the Future'. Cli-Fi and Design Fictions as Dialogical Frameworks for Expert Engagements. The Design Journal, 20(sup1), S1817-S1826. https://doi.org/10.1080/14606925.2017.1352679

Römgens, B. (2016). Roadmapping. In P. Van der Duin (Ed.), Foresight in Organizations. Routledge.

Sanders, L., \& Stappers, P. J. (2013). Convivial Toolbox: Generative Research for the Front End of Design. Laurence King Publishing.

Sterling, B. (2009). Cover Story: Design Fiction. ACM Interactions, 16(3), 20-24.

Stickdorn, M., Hormess, M. E., Lawrence, A., \& Schneider, J. (2018). This Is Service Design Doing: Applying Service Design Thinking in the Real World. O'Reilly Media.

Svenfelt, Å., Alfredsson, E. C., Bradley, K., Fauré, E., Finnveden, G., Fuehrer, P., Gunnarsson-Östling, U., Isaksson, K., Malmaeus, M., Malmqvist, T., Skånberg, K., Stigson, P., Aretun, Å., Buhr, K., Hagbert, P., \& Öhlund, E. (2019). Scenarios for sustainable futures beyond GDP growth 2050. Futures, 111, 1-14. https://doi.org/10.1016/j.futures.2019.05.001

Svenfelt, Å., Engström, R., \& Höjer, M. (2010). Use of explorative scenarios in environmental policymaking-Evaluation of policy instruments for management of land, water and the built environment. Futures, 42(10), 1166-1175. https://doi.org/10.1016/j.futures.2010.06.002

Tarrow, S. (1995). Bridging the Quantitative-Qualitative Divide in Political Science. American Political Science Review, 89(2), 471-474. https://doi.org/10.2307/2082444

Author Bios:

Cathrine Kulsbjerg Løgager is a User Experience and Service Designer working at a Danish SaaS Company, as well as a research Affiliate at the Service Design Lab at Aalborg University. Her work focuses on foresight and service design.

Luca Simeone is an Associate Professor at Aalborg University and has conducted research and teaching activities in various universities (Harvard, MIT, Milan Polytechnic, Malmö University, University of the Arts London), mostly exploring the managerial, strategic and organizational aspects of design.

G. Mauricio Mejía is an Associate Professor of Design at Arizona State University. His research focuses on approaches of design for change incorporating theory, strategic thinking, and futures studies. He explores how professional designers or stakeholders can design for change collaboratively. 